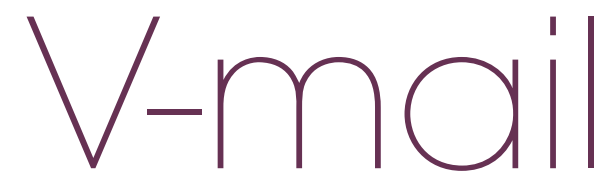

Send your views to

vitaleditorial@nature.com

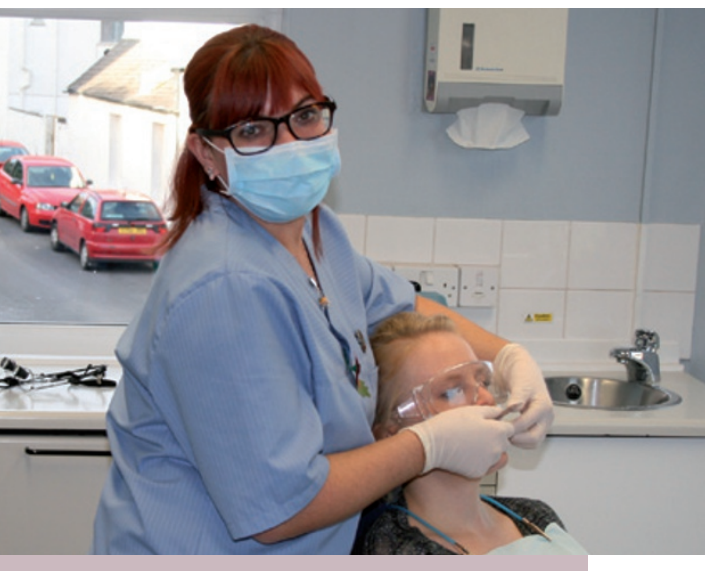

LETTER

\title{
TAKING THE PERFECT IMPRESSION
}

I am a registered dental nurse and implant nurse working in a modern seaside practice in sunny Devon. I have been nursing now for four and a half years and was starting to get that feeling of work being repetitive and wanted to spice things up a little.

I had heard that nurses are now

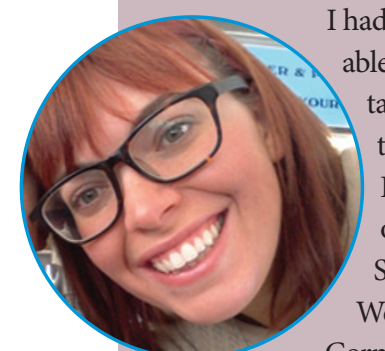
able to undertake impression taking so I set about finding the nearest course to me. I finally managed to find one in Torbay held by Sonia Jones who is South West DCP advisor for Cornwall and Devon and who I must add is an amazing teacher and really does encourage nurses to go for it! I was so thrilled when I heard I had got a place on the course as places are limited.

I attended the course on 1 September 2012. It was a fun-filled day with theory in the morning, learning all about anatomy, types of impressions, landmarks of the mouth, communication, infection control, consent, confidentiality, complaints (I hope you never need to deal with that one!), writing patient notes, PPE, preparing the surgery and materials needed, complications and wax bite recordings ... and that was just the morning.

The fun really began in the afternoon when we were split into two groups and were able to practise all types of techniques and tricks for taking the perfect impression. We were also taught how to take a wax bite.

After the day of training I was let loose in the surgery of course, under the supervision of Peter Zeltmann, the dentist I work with full time, who was very supportive and a great teacher. I really think you need $100 \%$ support from the dentist you work with or else it will be a struggle to practise your new skills.

We were asked to take ten alginate impressions on patients and record our experience in the books we were given. We had to write: what was prescribed to us to do, how the patient reacted, how you feel you did and what you may do differently next time. There was then a section for the supervising dentist to fill in writing about how you did.

I do admit taking the impressions was harder than I thought, making sure all the necessary landmarks of the mouth are recorded on the impression, and of course dealing with patients who do not have a great gag reflex!

I was very lucky and managed to take well over the ten impressions needed, so I do feel I gained good confidence for the exam.

I took the exam on Saturday 3 November 2012 and Sonia and the team created a relaxed atmosphere. We were all given a number and had to be each other's patients during the exam. We had to take an upper and lower alginate impression for study models and a wax bite. We had to do the whole sequence as we would by ourselves in the surgery with Sonia and Gordon watching in the background marking what we do ie: greeting the patient, handwashing, PPE, trying for tray size and so on. I am really pleased to say I passed and so did everyone else in my group.

I am so excited to think I can now take safe and good impressions on patients and about being able to bring this into my day to day life in the surgery. I love the interaction with patients.

I urge every dental nurse to do this course and bring more spice in to your day to day nursing.

I would like to say a big thank you to Sonia Jones for organising the course, Gordon Yeates who is General Practitioner in Torquay and Bridget Ashton who is VT tutor and General Practitioner in Plymouth for all the help on the two days we attended. Over 100 certificates of competence have been awarded by the South West Deanery tutors for impression taking since the courses started in 2011.

You can book this course on the South West Dental Postgraduate Deanery website www. Bristol.ac.uk/dentalpg.

\section{Gemma Slee RDN}

Gemma wins an Oral-B Triumph 5000 with SmartGuide worth $£ 179.99$.

\section{OLD SCHOOL} \section{DENTAL NURSES}

I just wanted to say that I thought the letter printed on page 4 of the winter issue of Vital, A job not a profession, was excellent. There are a lot of us old school dental nurses who are of the same opinion. Thanks for printing it.

\section{Jo Barclay, Dental Nurse Manager \\ London}

\section{COVER STARS: WHERE ARE YOU NOW?}

To celebrate Vital's $10^{\text {th }}$ anniversary this year, we would like to ask all past Vital cover stars to contact us and let us know what you have been up to. We plan to run a Where are they now? style article later this year.

Please email the Editor,

Kate Maynard, on vitaleditorial@ nature.com.

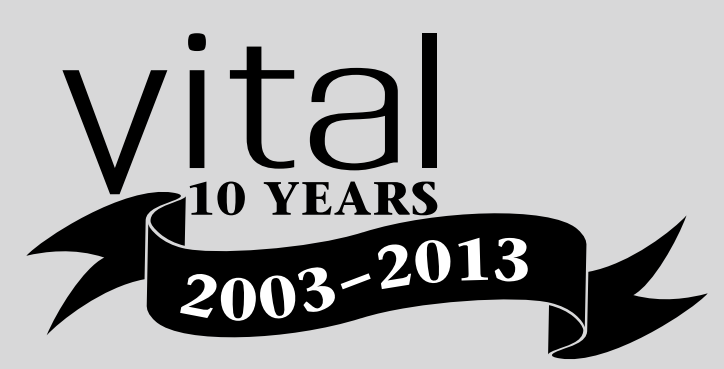

